\title{
DISTRIBUIÇÃO TRIBUTÁRIA E EXECUÇÃO ORÇAMENTÁRIA DOS MUNICÍPIOS DA REGIÃO SUL A PARTIR DE INDICADORES
}

\section{TAX DISTRIBUTION AND BUDGET EXECUTION OF SOUTH MUNICIPALITIES FROM INDICATORS}

\begin{abstract}
“A versão preliminar do artigo foi aprovada e apresentada no IX Seminário Internacional sobre Desenvolvimento Regional, realizado em Santa Cruz do Sul, RS, Brasil, 11 a 13 de setembro de 2019 ISSN: 2447-4622"
\end{abstract}

\section{RESUMO}

O estudo possui como objetivo central verificar se existe relação entre a Distribuição Tributária e a Execução Orçamentária nas áreas da Saúde, Educação e Emprego e Renda, bem como se essa relação é alterada quando se avaliam os municípios por categorias de indicadores. Utilizou-se a coleta de dados secundários de 592 municípios dos três estados da região sul, selecionados probabilisticamente. Um conjunto de hipóteses testadas por meio da correlação de Pearson, considerando a configuração regional e estadual, indicou relação significativa entre a Distribuição Tributária e a Execução Orçamentária das três áreas pesquisadas. Ainda, verificou-se que, nos municípios com maior PIB Per Capita há também uma Distribuição Tributária e Execução Orçamentária mais elevada, podendo haver benefícios advindos do atual modelo distributivo. A falha no modelo distributivo também fica evidente quando se observa que o aumento da Contribuição Tributária Per Capita e da População incorre na redução média dos valores per capita da Distribuição Tributária e da Execução Orçamentária. A partir dos resultados encontrados, lança-se uma reflexão sobre a necessidade de revisão do atual modelo distributivo, pois está havendo uma tendência de os municípios que mais contribuem para a arrecadação dos estados e união receberem menores valores per capita.

Palavras-chave: Indicadores Econômicos. Indicadores Demográficos. Saúde. Educação. Emprego e Renda.

\begin{abstract}
The main objective of the study is to verify if there is a relationship between Tax Distribution and Budget Execution in the Health, Education and Employment and Income areas, as well as whether this relationship is altered when assessing municipalities by categories of indicators. Secondary data collection was used from 592 municipalities in the three southern states, selected probabilistic sampling. A set of hypotheses tested using Pearson's correlation, considering the regional and state configuration, indicated a significant relationship between Tax Distribution and Budget Execution in the three areas. Still, it was found that, in the municipalities with the highest GDP per capita, there are also a higher Tax Distribution and Budget Execution, with benefits arising from the current distributive model. The failure in the distributive model is also evident when observed that the increase in Per Capita Tax Contribution and Population incurs an average reduction in the per capita values of Tax Distribution and Budget Execution. Based on the results found, a reflection is launched on the need to review the current distributive model, as there is a tendency for the municipalities that most contribute to the collection of states and unions receive lower amounts per capita.
\end{abstract}

Keywords: Economic Indicators. Demographic Indicators. Relationship. Health. Education. Employment and Income.
Ari Söthe

Doutor em Desenvolvimento Regional pela Fundação Universidade Regional de Blumenau (PPGDR-FURB). Professor Adjunto da Universidade Federal da Fronteira Sul, Cerro Largo- RS - Brasil. Atua no Curso de Administração da Universidade Federal da Fronteira Sul. Endereço eletrônico: ari.sothe@uffs.edu.br. Endereço para correspondência: Av. Jacob Reinaldo Haupenthal, 1580 - Bairro São Pedro, Cerro Largo - RS. CEP: 97900-000

\section{Monize Sâmara Visentini}

Doutora em Administração pela Universidade Federal do Rio Grande do Sul (PPGA-UFRGS). Professora Adjunta da Universidade Federal da Fronteira Sul, Cerro Largo- RS - Brasil. Atua no Programa de Pós Graduação em Desenvolvimento e Políticas Públicas da Universidade Federal da Fronteira Sul. Endereço eletrônico: monize.visentini@uffs.edu.br. Endereço para correspondência: Av. Jacob Reinaldo Haupenthal, 1580 - Bairro São Pedro, Cerro Largo - RS. CEP: $97900-000$

\section{Laura Luiza Mallmann Franke} Mestranda do Programa de Pós Graduação em Desenvolvimento e Políticas Públicas da Universidade Federal da Fronteira Sul. Endereço eletrônico: lauraluizafranke@ gmail.com. Endereço para correspondência: Av. Jacob Reinaldo Haupenthal, 1580 Bairro São Pedro, Cerro Largo - RS. CEP: 97900-000 


\section{INTRODUÇÃO}

O atual modelo federativo, mais conhecido como Federalismo Fiscal e definido pela Constituição Federal de 1988, em seus artigos 145 a 162, atribuiu responsabilidades, competências tributárias e distributivas a todos os entes do território nacional. Se por um lado, os entes federados gozam de autonomia administrativa, auto-organização e normatização; por outro, carregam a responsabilidade da descentralização de demandas por diversas políticas públicas.

Tais políticas são originadas das demandas sociais e requerem dos governos a definição de prioridades, atribuições e recursos para a sua manutenção e implementação. Em especial, nas áreas da saúde, educação e emprego e renda, cabe aos governos municipais o atendimento de políticas públicas, sendo essa responsabilidade ampliada por meio de cláusulas constitucionais que exigem a aplicação mínima de recursos orçamentários especialmente nas duas primeiras áreas.

Entretanto, a concentração dos recursos, principalmente no governo central, diminui a capacidade de planejamento e execução dos orçamentos municipais para atender as demandas locais. Tedesco (2014) argumenta que os estados regionais os entes subnacionais desenvolvem suas atividades a partir de meras delegações de atribuições e poderes estabelecidos na constituição. Em complemento, Fonseca (2017) critica o modelo federalista acordado por meio do pacto federativo selado na constituição de 1988, pois, o governo central preservou a capacidade e a autoridade, arrecadando dois terços da carga tributária, ao mesmo tempo em que transfere aos estados e municípios as atribuições típicas do setor público. Assim, o atual modelo não beneficia a distribuição dos recursos aos municípios a partir da sua capacidade contributiva, mas amplia a centralização dos recursos e a descentralização das responsabilidades.

A partir dessa perspectiva se apresenta esta investigação, que objetiva verificar se existe relação entre a Distribuição Tributária e a Execução Orçamentária nas áreas da Saúde, Educação e Emprego e Renda. Este estudo busca detalhar características dos municípios considerando particularidades, a partir dos indicadores econômicos e demográficos. Assim, surge um objetivo secundário, que visa verificar se a relação entre a Distribuição Tributária e Execução Orçamentária nas áreas da Saúde, Educação e Emprego e Renda é alterada quando se avaliam os municípios por categorias de indicadores econômicos e demográficos.

A base teórica que fundamenta a relação entre a Distribuição Tributária e a Execução Orçamentária municipal a partir de amostras por indicadores econômicos (Contribuição Tributária Per Capita e Produto Interno Bruto (PIB) Per Capita) e demográficos (População) é bastante limitada. No entanto, no que se refere à Contribuição Tributária, Veloso (2008) ressalta a necessidade de novos critérios que considerem o esforço tributário dos governos recebedores, e não apenas indicadores populacionais e de renda. Ainda, Rodrigues (2004) indica que há uma relação negativa entre o esforço arrecadatório dos municípios e as transferências de recursos da União. No tocante ao PIB Per Capita, Conti (2001) indica que as diferenças econômicas e de renda entre as regiões pressupõem uma necessidade de distribuição diferenciada dos recursos, buscando a redução dessas desigualdades.

Por fim, quanto à População, Abreu (2001) destaca que os municípios com maior população possuem maior arrecadação e dependência proporcional às transferências intergovernamentais. Em adição, Moratta (2015) reforça a dependência dos municípios com até dez mil habitantes em relação às transferências intergovernamentais. Esses estudos já apresentam algumas referências do comportamento da Distribuição Tributária e Execução Orçamentária a partir de alguns indicadores municipais.

Dados os objetivos apresentados, este estudo é direcionado para os governos municipais do sul do país, permitindo mensurar a relação entre a Distribuição Tributária federal e estadual e a execução dos orçamentos. A escolha desses municípios se deu, principalmente, pela sua aproximação geográfica, compreendida como a menor formação regional brasileira. Para tanto, consideram-se nas análises avaliações de nível regional (amostra de municípios da região sul do país) e estadual (amostra de municípios por estado da região sul). Entende-se que, dessa forma, pode-se ter além de uma visão global dos efeitos da Distribuição Tributária sobre a Execução Orçamentária no conjunto de municípios da região em estudo, um melhor entendimento de possíveis diferenças entre os municípios dos três estados investigados (Santa Catarina, - SC, Paraná - PR e Rio Grande do Sul - RS).

A opção pela Contribuição Tributária Per Capita como indicador econômico de análise se justifica por corresponder ao montante dos tributos recolhidos pela totalidade de contribuintes de cada município para os cofres do estado e União, servindo de base para a distribuição das denominadas devoluções tributárias aos municípios (PRADO, 2003). Já a aplicação do PIB Per Capita faz-se, especialmente, por este considerar a dimensão econômica do desenvolvimento (PNUD, 2016). Por fim, a escolha do indicador demográfico da População se deve especialmente à vinculação de grande parcela dos recursos distribuídos aos municípios a partir do número de habitantes. Nesse sentido, destacam-se os dois principais fluxos de básicos de distribuição de receitas: o Fundo de Participação dos Municípios (FPM), de natureza eminentemente redistributiva; e a Cota-Parte do ICM (posteriormente ICMS - Imposto sobre Circulação de Mercadorias e Serviços) essencialmente uma devolução tributária (ARAÚJO, 2013).

Estudos foram desenvolvidos ao longo das últimas décadas, isoladamente sobre cada um dos temas que abrange o modelo distributivo e sua capacidade de impactar positivamente a execução dos orçamentos municipais (Abreu, 2001; Nascimento, 2010; Brito, 2011; Politi \& Mattos, 2016). No entanto, este estudo procura contribuir na qualificação do atual modelo distributivo, diante da problemática do desequilíbrio presente entre descentralização de responsabilidades, recursos distribuídos e níveis de execução de gastos. Destaca-se que se trata de um pleito antigo por parte dos municípios a mudança da forma de distribuição dos recursos arrecadados pelos governos estadual e federal. 
Desse modo, as conclusões deste estudo poderão fundamentar as demandas municipais e estimular a ampliação da transparência e a participação popular na gestão pública dos municípios. Os resultados permitirão também aos gestores municipais justificar, perante a sociedade, eventuais faltas de investimentos nas áreas de saúde, educação e emprego e renda, motivadas pela distribuição dos tributos.

\section{MODELO DISTRIBUTIVO BRASILEIRO E A EXECUÇÃO DOS ORÇAMENTOS MUNICIPAIS}

O sistema distributivo público no Brasil nasceu efetivamente com a reforma tributária de 1967, criando normas e um sistema nacional de repartição das receitas tributárias, seguindo-se suas bases até hoje. Burgo (2013) destaca que apesar de o Brasil ter sido construído no signo da centralização, a Constituição de 1988 conseguiu aumentar a descentralização, ampliando as atribuições e distribuições tributárias aos governos subnacionais. Nesse sentido, Carvalho (2010, p. 134) complementa que "não se pode negar que a Constituição de 1988 pretendeu viabilizar a descentralização fiscal; basta lembrar que houve o aumento da participação dos entes subnacionais na receita pública, enquanto a do poder central diminuiu". Por outro lado, lembra o mesmo autor, que a referida descentralização não se deu por intermédio do planejamento estruturado, que preza pela descentralização de encargos e de recursos, o que não ocorreu no mesmo nível e de forma clara.

Fica evidente, nesse cenário, que o período que antecedeu a Constituição de 1988 é marcado pela manutenção do centralismo fiscal, surgindo, a partir de então, maior autonomia de competências tributárias, bem como ampliando o nível de recursos dos governos subnacionais. Dessa maneira, o modelo de federalismo fiscal, constituído a partir de 1967 e continuado em 1988, tornou-se descentralizador de recursos e centralizador de responsabilidades, o que dificulta a definição do papel de cada ente da federação. Trata-se de um debate sensível, porém necessário acerca da reforma tributária.

A descentralização de responsabilidades e de recursos é fundamental para o fortalecimento dos governos estaduais e locais. Consequentemente, a natureza tributária e fiscal é um dos aspectos mais importantes nas disputas entre níveis de governo nos estados nacionais, independentemente de serem federais ou unitários (Arretche, 2004). A autora complementa que a autonomia dos governos é significativamente vinculada à sua autoridade tributária e fiscal. Os governos locais podem contar com recursos para atender às demandas apresentadas pela comunidade. No entanto, não possuem autonomia suficiente para definir sua própria agenda de políticas públicas, pois suas políticas são financiadas basicamente por transferências vinculadas.

O modelo de federalismo fiscal, ausente da descentralização de políticas, parte inicialmente, da inexistência de autonomia financeira para sua execução, dependendo principalmente do governo central. Por outro lado, a política de gastos, traçada pelo governo central, compromete a liberdade dos governos subnacionais em definir suas próprias políticas públicas (Carvalho, 2010).

O modelo de distribuição tributária estabelecido pela Constituição Federal de 1988 desarticulou o estado, com respeito às prioridades da política de desenvolvimento. Pela falta de revisão dos critérios de rateio dos Fundos de Participação de Estados e Municípios pela Receita Federal, que ocasiona profundos desequilíbrios na distribuição da receita per capita entre os municípios, beneficiando principalmente as unidades de menor população. Estudos como os de Silva (2002), Cossio (2002), Porsse (2005), Lima (2006), Liparizi (2006) e Santos (2012) merecem ser lembrados para contribuir na discussão do tema do federalismo fiscal que define a arrecadação e a distribuição tributária brasileira.

A distribuição tributária federal e estadual serve de base central para o planejamento e posterior execução orçamentária. O planejamento corresponde a um processo dinâmico de racionalização coordenada das opções, com vista na tomada de decisões mais adequadas e racionais, maximizando o uso dos recursos disponíveis (Matias-Pereira, 2010). Assim, o planejamento se concretiza por meio da figura da orçamentação, ao estabelecer metas, diretrizes, programas e ações a serem desenvolvidas ao longo do período de vigência da respectiva lei de caráter orçamentário e define a alocação de recursos às ações a serem desenvolvidas.

Nessa linha, Rebouças (2014) frisa que o sistema orçamentário da Constituição de 1988 tem uma engenharia que integra e coordena a lei do Plano Plurianual (PPA), a Lei de Diretrizes Orçamentárias (LDO) e a Lei Orçamentária Anual (LOA). De acordo com esse autor (p. 22), "no ápice desse sistema está o PPA, principal lei de planejamento público, nos termos constitucionais, que vinculará a LDO, a LOA". O orçamento público tem como função especial o atendimento das prioridades e metas estabelecidas, assim como permite a avaliação e revisão constante dos objetivos propostos pelo governo.

Para o atendimento das necessidades de políticas públicas fundamentais, a própria constituição de 1988 já estabelece limites mínimos de execução dos orçamentos municipais em algumas áreas como educação e saúde. De um lado a Emenda Constitucional n ${ }^{\circ}$ 29/2000 determina que os municípios devam aplicar no mínimo $15 \%$ de suas receitas em serviços de saúde. Por outro, o artigo 212 da Constituição Federal buscou garantir a execução mínima de $25 \%$ dos recursos dos municípios na educação (BRASIL, 2004).

No Quadro 1 são apresentados alguns estudos que se destacam quanto a investigação da relação entre o modelo distributivo e a execução de gastos dos municípios. 
Quadro 1 - Estudos anteriores sobre distribuição tributaria e execução orçamentária e seus achados

\begin{tabular}{|c|c|c|c|}
\hline Autor/Ano & Tema & Objetivo & Principais Achados \\
\hline $\begin{array}{c}\text { Oliveira } \\
\text { (2010) }\end{array}$ & $\begin{array}{l}\text { Impacto das emancipações } \\
\text { sobre a distribuição } \\
\text { orçamentária nos municípios } \\
\text { gaúchos }\end{array}$ & $\begin{array}{l}\text { Apresentar as discussões sobre } \\
\text { as emancipações municipais e o } \\
\text { federalismo fiscal no Brasil. }\end{array}$ & $\begin{array}{c}\text { Observa que os municípios emancipados } \\
\text { melhoraram suas arrecadações e a } \\
\text { distribuição das receitas orçamentárias } \\
\text { no Estado do RS melhorou após as } \\
\text { emancipações. }\end{array}$ \\
\hline $\begin{array}{c}\text { Sakuray } \\
(2013)\end{array}$ & $\begin{array}{l}\text { Efeitos das transferências nos } \\
\text { gastos públicos municipais. }\end{array}$ & $\begin{array}{l}\text { Verificar as variações } \\
\text { das despesas públicas } \\
\text { municipais são simétricas as } \\
\text { varrições das transferências } \\
\text { intergovernamentais. }\end{array}$ & $\begin{array}{l}\text { Constatou a simetria entre as } \\
\text { transferências e o gasto, assim como, a } \\
\text { mudança no tipo de gasto a partir das } \\
\text { variações das transferências. }\end{array}$ \\
\hline $\begin{array}{l}\text { Brito } \\
(2011)\end{array}$ & $\begin{array}{l}\text { Efeitos das transferências } \\
\text { intergovernamentais sobre as } \\
\text { finanças públicas. }\end{array}$ & $\begin{array}{l}\text { Diagnosticar as transferências } \\
\text { a partir da sistematização das } \\
\text { informações quanto à origem, o } \\
\text { valor e o destino. }\end{array}$ & $\begin{array}{c}\text { Apresenta algumas proposições para o } \\
\text { sistema de transferências e composição } \\
\text { dos gastos a fim de contribuir com uma } \\
\text { maior eficiência fiscal. }\end{array}$ \\
\hline $\begin{array}{c}\text { Moratta } \\
(2015)\end{array}$ & $\begin{array}{l}\text { A participação } \\
\text { das transferências } \\
\text { intergovernamentais no } \\
\text { crescimento econômico dos } \\
\text { municípios do Estado de } \\
\text { Santa Catarina. }\end{array}$ & $\begin{array}{l}\text { Identificar a (in)dependência } \\
\text { orçamentária em } \\
\text { relação às transferências } \\
\text { intergovernamentais dos } \\
\text { municípios com até } 10.000 \\
\text { habitantes no Estado de Santa } \\
\text { Catarina e seu reflexo para o } \\
\text { crescimento econômico. }\end{array}$ & $\begin{array}{l}\text { Demonstra que a dependência dos } \\
\text { municípios em relação às transferências } \\
\text { intergovernamentais } \\
\text { não influencia o crescimento econômico. }\end{array}$ \\
\hline $\begin{array}{l}\text { Politi e } \\
\text { Mattos } \\
(2016)\end{array}$ & $\begin{array}{l}\text { Aspectos equitativos e } \\
\text { eficientes das transferências } \\
\text { intergovernamentais nos } \\
\text { municípios brasileiros. }\end{array}$ & $\begin{array}{l}\text { Identificar os aspectos } \\
\text { redistributivos e de eficiência das } \\
\text { transferências para municípios } \\
\text { no Brasil. }\end{array}$ & $\begin{array}{l}\text { Conclui que as regiões metropolitanas } \\
\text { mais populosas do país são as mais } \\
\text { prejudicadas quanto ao benefício gerado } \\
\text { pelas transferências intergovernamentais, } \\
\text { sugerindo que a sua distribuição pode ser } \\
\text { aprimorada em termos de equidade e, } \\
\text { sobretudo, eficiência. }\end{array}$ \\
\hline
\end{tabular}

Fonte: elaborado pelos autores

Diante da definição das responsabilidades que cabem aos governos municipais, a avaliação da eficiência desses governos tem sido feita a partir de indicadores (Januzzi, 2012). Nesse sentido, os indicadores econômicos e demográficos podem servir de referência para avaliar se a distribuição dos recursos e sua execução nos municípios têm refletido nos resultados das políticas públicas locais.

\section{INDICADORES ECONÔMICOS E DEMOGRÁFICOS}

Após a Reforma Constitucional de 1988, a descentralização fiscal fez com que estados e municípios tivessem maior autonomia política, legislativa e financeira. Com isso, para que os municípios pudessem desenvolver suas atividades, além das transferências intergovernamentais, começaram a ter a capacidade de obter receita própria através da exploração de seu patrimônio, bem como através das contribuições executadas pelos tributos municipais (Massardi \& Abrantes, 2015). Sob o arcabouço teórico, diversos autores buscaram identificar a relação entre os indicadores de Contribuição Tributária, PIB Per Capita e População, com a Distribuição Tributária e a Execução Orçamentária municipal, sendo alguns desses estudos discutidos nesta seção.

Bronuzi, Ferreira, Abrantes e Arantes (2011) investigaram os efeitos que as transferências intergovernamentais e a arrecadação tributária têm sobre os indicadores sociais de saúde e educação no estado de Minas Gerais. Mais precisamente, analisaram se esses municípios podem ser distinguidos por meio dos valores do PIB Per Capita, transferências sociais, seguridade social, receitas próprias, quota-parte do ICMS e arrecadação tributária. Os autores constataram que os indicadores de arrecadação tributária e quota-parte do ICMS são as variáveis que apresentam distinção da importância das receitas públicas como fonte de incentivo as demandas sociais básicas advindas da população. Já as variáveis transferências sociais, transferências intergovernamentais, seguridade social e a própria produção econômica dos municípios não possuem efeito significativo na discriminação dos municípios quando se tratam dos serviços da saúde e da educação.

Já Massardi e Abrantes (2014) classificam os municípios mineiros em relação à composição de suas receitas. A escolha do estado de Minas Gerais, segundo os autores, se deve pelo fato de ser o com maior heterogeneidade econômica e social e também possuir o maior número de municípios. Para tal pesquisa, os municípios foram divididos em clusters. Como resultados, tem-se que os municípios cujo nível de atividade econômica é mais elevado têm melhor uso das suas tributações, como o Imposto sobre Predial e Territorial Urbano (IPTU) e Imposto Sobre Serviços de Qualquer Natureza 
(ISSQN). Em contrapartida, àqueles municípios considerados de pequeno porte e que se localizam em regiões mais pobres, possuem maior dependência das transferências intergovernamentais.

O estudo de Massardi e Abrantes (2015) analisou o esforço de arrecadação dos municípios do estado de Minas Gerais e também sua relação com o nível de dependência de transferências intergovernamentais, dando ênfase ao FPM e com o nível de desenvolvimento socioeconômico mensurado através do IFDM (Emprego e Renda, Educação e Saúde). Os resultados mostram que ainda existe uma grande quantidade de municípios que não exploram sua capacidade de arrecadação. Ademais, os autores confirmaram que municípios que têm uma grande dependência do FPM, têm também um baixo índice de esforço fiscal, ou seja, fica evidente que as transferências intergovernamentais influenciam negativamente o esforço de arrecadação. Apesar disso, em se tratando do IFDM, os municípios com maior desenvolvimento socioeconômico possuem também maiores índices de esforço fiscal e menor dependência do FPM.

Vieira, Abrantes, Almeida, Silva e Ferreira (2017) também investigaram os municípios do estado de Minas Gerais com o objetivo de compreender quais as características possuem influência na arrecadação tributária própria desses municípios. Os autores pesquisaram a influência da arrecadação tributária nos seguintes indicadores: PIB, Valor Adicionado Fiscal (VAF), Valor Adicionado da Agropecuária (VAA), Valor Adicionado da Indústria (VAI), Valor Adicionado dos Serviços (VAS), Cota do ICMS, FPM, proporção de empresas, taxa de urbanização, proporção de pessoas ocupadas e renda per capita. Como resultados, obteve-se que quanto maior for o dinamismo econômico dos municípios, maior tende a ser a arrecadação tributária municipal. Além disso, que a infraestrutura e as condições demográficas possuem impacto positivo e crescente naqueles municípios que têm maior poder de arrecadação. E, por fim, que o maior repasse de transferências intergovernamentais, ou seja, através do FPM, dificulta a arrecadação própria apenas para os municípios que possuem maior fator econômico (PIB, VAF, VAS e VAI). As conclusões indicam que os aspectos que circunstanciam a arrecadação tributária própria municipal variam de município para município.

\section{PROCEDIMENTOS METODOLÓGICOS}

A presente pesquisa é classificada como descritiva, quantitativa, documental e de corte transversal. A pesquisa foi alicerçada na coleta das informações por meio das páginas eletrônicas das bases de dados apresentadas na Tabela 1.

Tabela 1 - Descrição e fontes dos dados utilizados

\begin{tabular}{|c|c|}
\hline Descrição dos dados & Fontes dos dados \\
\hline $\begin{array}{c}\text { Distribuição Tributária, Execução Orçamentária } \\
\text { (Saúde, Educação e Emprego e Renda) }\end{array}$ & $\begin{array}{c}\text { Sistema de Informações Contábeis e Fiscais do Setor Público Brasileiro } \\
\text { (SICONFI) }\end{array}$ \\
Contribuição Tributária Per Capita & Receita Federal do Brasil (RFB); \\
& Secretaria de Estado da Fazenda de Santa Catarina (SEF/SC); \\
Secretaria de Estado da Fazenda do Rio Grande do Sul (SEF/RS); & Secretaria de Estado da Fazenda do Paraná (SEF/PR). \\
Instituto Brasileiro de Geografia e Estatística (IBGE)
\end{tabular}

Fonte: dados da pesquisa

A população objeto do estudo abrange os 1.191 municípios da região sul do país. A amostra é classificada como probabilística e compreende 592 municípios. A seleção dos municípios integrantes da amostra foi realizada por meio de amostragem probabilística aleatória simples, por estado, com 5\% de erro amostral, conforme indicado por Barbetta (2008), através da Equação 1, sendo $N=$ tamanho da população; $E_{0}^{2}=$ erro amostral; $n=$ tamanho da amostra.

$$
n=\frac{N \cdot\left(1 / E_{0}^{2}\right)}{N+\left(1 / E_{0}^{2}\right)}
$$

Aplicando-se a Equação 1, a composição da amostra para cada um dos estados investigados é apresentada na Tabela 2.

Tabela 2 - Cálculo da amostra por estado da região sul

\begin{tabular}{c|c}
\hline Estado & Cálculo do Extrato (amostras) \\
\hline Paraná & $\mathrm{n}=\frac{399 \times 400}{399+400}+200$ municípios \\
Santa Catarina & $\mathrm{n}=\frac{295 \times 400}{295+400}=170$ municípios \\
Rio Grande do Sul & $\mathrm{n}=\frac{497 \times 400}{497+400}$ \\
\hline
\end{tabular}

Fonte: dados da pesquisa. 
Os dados da amostra dos 592 municípios foram coletados entre os anos de 2017 e 2018, compreendendo o período de 2009 a 2013. A indisponibilidade até o momento da coleta dos índices de desenvolvimento dos municípios nas três áreas a partir do exercício de 2014 limitou a análise dentro desse espaço temporal. Para identificar os comportamentos distintos em diferentes grupos de municípios, e atender ao objetivo secundário do estudo, os indicadores demográficos e econômicos foram organizados em classes de Quartis, conforme apresentado na Tabela 3, considerando as avaliações de nível regional (amostra total de municípios) e estadual (SC, PR e RS).

Tabela 3 - Indicadores demográficos e econômicos e respectivos quartis

\begin{tabular}{|c|c|c|c|c|c|c|c|c|c|}
\hline \multirow{2}{*}{ Indicadores } & \multirow{2}{*}{ Quartis } & $\mathbf{N}$ & Frequência & $\mathbf{N}$ & Frequência & $\mathbf{N}$ & Frequência & $\mathbf{N}$ & Frequência \\
\hline & & \multicolumn{2}{|c|}{ Amostra geral } & \multicolumn{2}{|r|}{$S C$} & \multicolumn{2}{|r|}{$P R$} & \multicolumn{2}{|r|}{$R S$} \\
\hline \multirow{2}{*}{$\begin{array}{c}\text { PIB Per Capita } \\
\text { (2013) }\end{array}$} & Q1 & 148 & Até $\mathrm{R} \$ 17.122,81$ & 42 & $\begin{array}{c}\text { Até } \mathrm{R} \$ \\
18218,987500\end{array}$ & 50 & $\begin{array}{c}\text { Até } \mathrm{R} \$ \\
15.508,25\end{array}$ & 55 & $\begin{array}{c}\text { Até } \mathrm{R} \$ \\
17.231,29\end{array}$ \\
\hline & Q4 & 148 & $\begin{array}{c}\text { Acima de } R \$ \\
29.527,49\end{array}$ & 42 & $\begin{array}{c}\text { Acima de } R \$ \\
31515,710000\end{array}$ & 50 & $\begin{array}{c}\text { Acima de } R \$ \\
26.967,00\end{array}$ & 55 & $\begin{array}{c}\text { Acima de } R \$ \\
30.984,58\end{array}$ \\
\hline \multirow{2}{*}{$\begin{array}{l}\text { Contribuição } \\
\text { Tributária } \\
\text { (2013) Per } \\
\text { Capita }\end{array}$} & Q1 & 148 & $\begin{array}{l}\text { Até } \mathrm{R} \$ \\
394,01\end{array}$ & 42 & Até $\mathrm{R} \$ 523,73$ & 50 & $\begin{array}{l}\text { Até } R \$ \\
283,80\end{array}$ & 55 & Até $\mathrm{R} \$ 478,15$ \\
\hline & Q4 & 148 & $\begin{array}{c}\text { Acima de } R \$ \\
1.830,07\end{array}$ & 42 & $\begin{array}{c}\text { Acima de } \mathrm{R} \$ \\
2.577,08\end{array}$ & 50 & $\begin{array}{c}\text { Acima de } R \$ \\
1.119,94\end{array}$ & 55 & $\begin{array}{c}\text { Acima de R\$ } \\
2.304,27\end{array}$ \\
\hline \multirow{2}{*}{$\begin{array}{l}\text { População } \\
(2010) \text { em } \\
\text { habitantes }\end{array}$} & Q1 & 148 & Até 3.889 & 42 & Até 3.423 & 50 & Até 5.449 & 55 & Até 2963 \\
\hline & Q4 & 148 & Acima de 16.138 & 42 & $\begin{array}{c}\text { Acima de } \mathrm{R} \$ \\
1.5426\end{array}$ & 50 & $\begin{array}{c}\text { Acima de } \\
17.253\end{array}$ & 55 & $\begin{array}{c}\text { Acima de } R \$ \\
14.158\end{array}$ \\
\hline
\end{tabular}

Fonte: dados da pesquisa

Optou-se por comparar os municípios dadas as características de mais baixos (Quartil 1 - Q1) e mais altos valores (Quartil 4 - Q4), a fim de verificar se há diferença significativa nos efeitos da Distribuição Tributária sobre os Execução Orçamentária, mensuradas a partir de indicadores demográficos e econômicos. Tendo em vista a literatura de suporte ao estudo, para os municípios dos três estados da região sul do país, as hipóteses do estudo são apresentadas na Tabela 4. 
Tabela 4 - Hipóteses do estudo

\begin{tabular}{|c|c|c|}
\hline Objetivo & Variáveis & Hipóteses \\
\hline \multirow[t]{5}{*}{$\begin{array}{l}\text { Verificar se existe relação } \\
\text { entre a Distribuição } \\
\text { Tributária e Execução } \\
\text { Orçamentária nas } \\
\text { áreas da Saúde, Educação e } \\
\text { Emprego e Renda. }\end{array}$} & DT e EOE & $\begin{array}{l}\text { H1a: Existe relação entre a Distribuição Tributária e a Execução } \\
\text { Orçamentária da área de Saúde (EOS) dos municípios da região sul } \\
\text { do país. } \\
\text { H1b: Existe relação entre a Distribuição Tributária e a Execução } \\
\text { Orçamentária da área de Educação (EOE) dos municípios da região } \\
\text { sul do país. }\end{array}$ \\
\hline & DT e EOER & $\begin{array}{l}\text { H1c: Existe relação entre a Distribuição Tributária e a Execução } \\
\text { Orçamentária da área de Emprego e Renda (EOER) dos municípios da } \\
\text { região sul do país. }\end{array}$ \\
\hline & DT e EOS & $\begin{array}{l}\text { H2a: Existe relação entre a Distribuição Tributária e a Execução } \\
\text { Orçamentária da área de Saúde quando se analisam os municípios da } \\
\text { região sul a partir de seu PIB Per Capita. }\end{array}$ \\
\hline & DT e EOE & $\begin{array}{l}\text { H2b: Existe relação entre a Distribuição Tributária e a Execução } \\
\text { Orçamentária da área de Educação quando se analisam os municípios } \\
\text { da região sul a partir de seu PIB Per Capita. }\end{array}$ \\
\hline & DT e EOER & $\begin{array}{l}\text { H2c: Existe relação entre a Distribuição Tributária e a Execução } \\
\text { Orçamentária da área de Emprego e Renda quando se analisam os } \\
\text { municípios da região sul a partir de seu PIB Per Capita. }\end{array}$ \\
\hline \multirow{5}{*}{$\begin{array}{l}\text { Verificar se a relação } \\
\text { entre a Distribuição } \\
\text { Tributária e Execução } \\
\text { Orçamentária nas } \\
\text { áreas da Saúde, } \\
\text { Educação e Emprego } \\
\text { e Renda é alterada } \\
\text { quando se avaliam os } \\
\text { municípios por categorias } \\
\text { de indicadores econômicos e } \\
\text { demográficos. }\end{array}$} & DT e EOS & $\begin{array}{l}\text { H3a: Existe relação entre a Distribuição Tributária e a Execução } \\
\text { Orçamentária da área de Saúde quando se analisam os municípios da } \\
\text { região sul a partir da sua Contribuição Tributária Per Capita. }\end{array}$ \\
\hline & DT e EOER & $\begin{array}{l}\text { H3b: Existe relação entre a Distribuição Tributária e a Execução } \\
\text { Orçamentária da área de Educação quando se analisam os municípios } \\
\text { da região sul a partir da sua Contribuição Tributária Per Capita. } \\
\text { H3c: Existe relação entre a Distribuição Tributária e a Execução } \\
\text { Orçamentária da área de Emprego e Renda quando se analisam os } \\
\text { municípios da região sul a partir da sua Contribuição Tributária Per } \\
\text { Capita. }\end{array}$ \\
\hline & DT e EOS & $\begin{array}{l}\text { H4a: Existe relação entre a Distribuição Tributária e a Execução } \\
\text { Orçamentária da área de Saúde quando se analisam os municípios da } \\
\text { região sul a partir da sua População. }\end{array}$ \\
\hline & DT e EOE & $\begin{array}{l}\text { H4b: Existe relação entre a Distribuição Tributária e a Execução } \\
\text { Orçamentária da área de Educação quando se analisam os municípios } \\
\text { da região sul a partir da sua População. }\end{array}$ \\
\hline & DT e EOER & $\begin{array}{l}\text { H4c: Existe relação entre a Distribuição Tributária e a Execução } \\
\text { Orçamentária da área de Emprego e Renda quando se analisam os } \\
\text { municípios da região sul a partir da sua População. }\end{array}$ \\
\hline
\end{tabular}

Fonte: dados da pesquisa

Vale ressaltar que as hipóteses apresentadas na Tabela 4 referem-se à análise global da amostra (592 municípios). Entretanto, também foram realizadas as análises por estado (SC, PR e RS), considerando as mesmas proposições. Desta forma, a título de simplificação, utiliza-se a mesma denominação da hipótese, incluindo-se a sigla do estado a que se refere. A título de exemplificação, $\mathbf{H}_{1} \mathbf{a}_{\text {sc }}$ refere-se à: "Existe relação entre a Distribuição Tributária e a Execução Orçamentária da área de Saúde (EOS) dos municípios do estado de SC.”. Esta lógica é válida para todas as hipóteses apresentadas na Tabela 4.

De posse dos dados, realizou-se a análise da relação existente entre Distribuição Tributária e Execução Orçamentária das três áreas pesquisadas. Inicialmente avaliou a análise do total dos 592 municípios pesquisados, bem como dos municípios por estado da região sul. Na sequência, dividiu-se a amostra por quartis a partir dos indicadores econômicos e demográficos. Como os três estados em análise apresentam desigualdades no perfil populacional e de contribuição tributária a análise dos dados regionais e estaduais foi realizada considerando os dados per capita, a fim de minimizar possíveis desvios que poderiam ocorrer. O programa de análises estatísticas Statistical Package for the Social Sciences (SPSS - versão 21.0) for Windows foi utilizado para a análise dos dados.

Procedeu-se de técnicas de análise como a estatística descritiva e Correlação de Pearson. Field (2009) indica que o Coeficiente de Correlação de Pearson (r) é também conhecido como o coeficiente de correlação produto-momento, ou seja, 
a medida do grau de associação entre duas variáveis, a direção dessa associação pode ser positiva ou negativa. A utilização do Coeficiente de Correlação de Pearson ( $r$ ) é justificada, pois nas hipóteses poderá ocorrer a influência somente em um dos sentidos, ou seja, da variável Distribuição Tributária sobre a variável Execução Orçamentária e não o contrário.

Field (2009, p. 129) explica que "[...] como o coeficiente de correlação é uma medida padronizada de um efeito observado, ele é uma medida comumente usada do tamanho do efeito, e que valores de $\pm 0,1$ representam um efeito pequeno, \pm 0,3, um efeito médio e $\pm 0,5$, um efeito grande". Para ampliar a compreensão dos resultados do Coeficiente de Correlação de Pearson (r), apresenta-se simultaneamente o coeficiente de determinação ${ }^{1}$. De acordo com Hair Jr., Babin, Money e Samouel (2005, p. 314) "além de examinar o coeficiente de correlação, muitas vezes o elevamos ao quadrado para obter o coeficiente de determinação ou $\mathrm{r}^{2}$ ".

\section{ANÁLISE DOS RESULTADOS}

Para atender aos objetivos do estudo é analisada neste capítulo a relação entre a Distribuição Tributária e a Execução Orçamentária nas áreas da saúde, educação e emprego e renda para os municípios da região sul do país, bem como para cada um dos estados dessa região. Isso se torna possível por meio da análise geral e, posteriormente, a partir da divisão em categorias dos indicadores de PIB Per Capita, Contribuição Tributária Per Capita e População.

\subsection{Relação entre Distribuição Tributária e Execução Orçamentária}

Na Tabela 5 são apresentadas as médias e desvio-padrão (DP) da Distribuição Tributária e Execução Orçamentária das três áreas pesquisadas.

Tabela 5 - Análise descritiva das variáveis estudadas

\begin{tabular}{c|c|c|c|c|c|c|c|c}
\hline \multirow{2}{*}{ Variável } & \multicolumn{2}{|c|}{ Amostra Geral } & \multicolumn{2}{c|}{ SC } & \multicolumn{2}{c}{ PR } & \multicolumn{2}{c}{ RS } \\
\cline { 2 - 8 } & Média* & DP & Média* & DP & Média* & DP & Média* & DP \\
\hline DT & $2.102,97$ & $2.067,90$ & $2.123,86$ & 943,84 & $1.943,98$ & $3.278,57$ & $2.230,19$ & $1.017,72$ \\
EOS & 501,19 & 193,89 & 528,36 & 189,44 & 450,38 & 157,83 & 526,15 & 217,09 \\
EOE & 539,93 & 181,55 & 597,70 & 177,39 & 462,63 & 140,28 & 565,34 & 194,26 \\
EOER & 134,82 & 142,70 & 173,83 & 168,06 & 72,12 & 71,18 & 161,45 & 151,18 \\
N & \multicolumn{2}{|c|}{592} & & & & 200 & & 222 \\
\hline
\end{tabular}

*dados per capita

Fonte: dados da pesquisa.

Denota-se por meio desses resultados que, na média per capita, tanto da análise geral dos 592 municípios, quanto de cada um dos estados, executam-se maiores montantes da Distribuição Tributária nas áreas da saúde e educação, se comparados à área de emprego e renda. Esses resultados são justificados a partir do que está estabelecido nos limites constitucionais de aplicação mínima na saúde e na educação, não existindo essa exigência de gastos mínimos na área de emprego e renda. Apesar desse cenário, os números da Tabela 5 merecem ser avaliados com ponderação, pois o desvio-padrão apresentado para as quatro variáveis é elevado, o que indica alta variabilidade de valores, a partir da média (Hair Jr. et al., 2005), das aplicações dos diferentes municípios da região sul do país.

Na Tabela 6 são demonstrados os resultados do Coeficiente de Correlação de Pearson (r) que testou as três primeiras hipóteses do estudo considerando a amostra geral e individual por estado.

1 "O coeficiente de correlação ao quadrado (conhecido como o coeficiente de determinação $\mathrm{R}^{2}$ ) é uma medida da quantidade de variação em uma variável que é explicada pela outra”. (FIELD, 2009, p. 143). 
Tabela 6 - Análise de correlação da Distribuição Tributária com a Execução Orçamentária das áreas pesquisadas

\begin{tabular}{|c|c|c|c|c|c|}
\hline $\begin{array}{l}\text { Grupo } \\
\text { amostral }\end{array}$ & Variáveis & $\begin{array}{l}\text { Correlação (r) } \\
\text { de Pearson }\end{array}$ & $\begin{array}{c}\text { Coeficiente de } \\
\text { Determinação } \\
\text { (r2) }\end{array}$ & Sig. $(\alpha)$ & Status da hipótese \\
\hline \multirow{3}{*}{ Geral } & DT e EOS & 0,380 ** & 0,144 & 0,000 & H1a - Suportada \\
\hline & DT e EOE & 0,322 ** & 0,104 & 0,000 & H1b - Suportada \\
\hline & DT e EOER & $0,306^{\star \star}$ & 0,094 & 0,000 & H1c - Suportada \\
\hline \multirow{3}{*}{ SC } & DT e EOS & 0,903 ** & 0,815 & 0,000 & $\mathrm{H} 1 \mathrm{a}_{\mathrm{SC}}-$ Suportada \\
\hline & DT e EOE & $0,754^{\star \star}$ & 0,569 & 0,000 & $\mathrm{H} 1 \mathrm{~b}_{\mathrm{SC}}$ - Suportada \\
\hline & DT e EOER & $0,870^{\star \star}$ & 0,757 & 0,000 & $\mathrm{H}_{1} \mathrm{c}_{\mathrm{sc}}-$ Suportada \\
\hline \multirow{3}{*}{ PR } & DT e EOS & $0,152^{\star}$ & 0,023 & 0,032 & $\mathrm{H} 1 \mathrm{a}_{\mathrm{PR}}$ - Suportada \\
\hline & DT e EOE & 0,149 * & 0,022 & 0,035 & $\mathrm{H} 1 \mathrm{~b}_{\mathrm{PR}}$ - Suportada \\
\hline & DT e EOER & 0,035 & 0,001 & 0,626 & $H 1 c_{P R}-$ Não Suportada \\
\hline \multirow{3}{*}{$\mathrm{RS}$} & DT e EOS & $0,918^{* *}$ & 0,843 & 0,000 & $\mathrm{H} 1 \mathrm{a}_{\mathrm{RS}}$ - Suportada \\
\hline & DT e EOE & $0,759 * *$ & 0,576 & 0,000 & $\mathrm{H}_{1} \mathrm{~b}_{\mathrm{RS}}$ - Suportada \\
\hline & DT e EOER & $0,754^{\star \star}$ & 0,569 & 0,000 & $\mathrm{H} 1 \mathrm{c}_{\mathrm{RS}}$ - Suportada \\
\hline
\end{tabular}

* A correlação é significativa no nível 0,05 (2 extremidades)

**A correlação é significativa no nível 0,01 (2 extremidades)

Fonte: dados da pesquisa.

Percebe-se, por meio da Tabela 6, que todas as hipóteses testadas foram suportadas, com exceção da hipótese $H 1_{C P R}$, indicando haver um efeito significativo das correlações entre o conjunto de variáveis testadas (sig. $\left.\leq 0,05\right)$. Para os estados de SC e RS a correlação entre as variáveis indicou um efeito forte (Field, 2009, p. 129) para a Execução Orçamentária das três áreas. Tais resultados podem ser explicados, parcialmente, a partir da vinculação constitucional à saúde e a educação de grande parcela dos recursos originados da Distribuição Tributária, não existindo essa vinculação obrigatória à área de emprego e renda. Assim, a vinculação dos recursos executados e distribuídos nos estados de SC e RS se mostra bastante forte, não prevalecendo essa força na relação das variáveis para o estado do PR.

Esses resultados distantes se justificam, parcialmente, por distorções significativas existentes entre os valores totais dos gastos e suas respectivas aplicações nas três áreas. Nesse sentido exemplifica-se com os dados do município de Ibaiti-PR, no ano de 2009, onde o valor total executado pelo município foi de $\mathrm{R} \$ 20.535 .350,36$ e o valor aplicado na saúde foi de $R \$ 210.032,42$ (1,02\%), quando o percentual mínimo de aplicação deveria ser de 15\%. Pode-se exemplificar também o município de Abatiá-PR, em 2013, que do total de gastos de $\mathrm{R} \$ 11.161 .591,72$ aplicou $\mathrm{R} \$ 2.064 .626,57$ $(18,5 \%)$ em emprego e renda.

Como consequência do pequeno efeito das relações observadas no estado do PR, a avaliação geral dos municípios da região sul indica relações significativas, mas de média intensidade. As três hipóteses são suportadas, sendo possível afirmar que a Distribuição Tributária possui relação com a Execução Orçamentária das áreas de saúde, educação e emprego e renda dos municípios da região sul.

Para atingir o objetivo secundário do estudo, nas seções 5.2, 5.3 e 5.4 é verificada se a relação entre a Distribuição Tributária e Execução Orçamentária nas áreas da Saúde, Educação e Emprego e Renda é alterada quando se avaliam os municípios, por estados e pela região, por categorias de indicadores econômicos e demográficos.

\subsection{Relação entre Distribuição Tributária e Execução Orçamentária a partir dos indicadores econômicos e demográficos}

O PIB Per Capita, corresponde ao primeiro indicador econômico utilizado para categorizar os municípios da amostra. Esta análise torna-se importante para identificar se os resultados se mantêm a partir de diferentes estratos da amostra. A escolha do indicador econômico do PIB Per Capita tem importância porque consolida a capacidade financeira de determinada População. Na Tabela 7 se apresentam as médias e desvio-padrão da Distribuição Tributária e Execução Orçamentária das três áreas pesquisadas, correspondentes aos municípios com menor e maior (Q1 e Q4) PIB Per Capita. 
Tabela 7- Análise descritiva das variáveis estudadas - Quartil PIB Per Capita

\begin{tabular}{c|c|c|c|c|c|c|c|c}
\hline \multirow{2}{*}{ Variável } & \multicolumn{2}{|c|}{ Amostra Geral } & \multicolumn{2}{c|}{ SC } & \multicolumn{2}{c|}{ PR } & \multicolumn{2}{c}{ RS } \\
\cline { 2 - 9 } & Média* & DP & Média* & DP & Média* & DP & Média* $^{*}$ & DP \\
\hline $\mathrm{DT}_{\mathrm{Q} 1}$ & $1.884,21$ & 770,91 & $2.233,86$ & 999,45 & $1.698,89$ & 656,14 & $1.826,97$ & 658,66 \\
$\mathrm{DT}_{\mathrm{Q} 4}$ & $2.249,50$ & $1.042,36$ & $2.073,70$ & 905,73 & $1.774,41$ & 583,76 & $2.768,43$ & $1.204,82$ \\
$\mathrm{EOS}_{\mathrm{Q} 1}$ & 457,37 & 169,34 & 530,22 & 198,86 & 429,25 & 151,10 & 431,50 & 156,96 \\
$\mathrm{EOS}_{\mathrm{Q} 4}$ & 561,94 & 211,53 & 552,35 & 183,08 & 464,95 & 138,31 & 665,36 & 239,38 \\
$\mathrm{EOE}_{\mathrm{Q} 1}$ & 506,79 & 156,87 & 594,39 & 192,56 & 447,62 & 112,79 & 495,89 & 136,05 \\
$\mathrm{EOE}_{\mathrm{Q} 4}$ & 602,93 & 197,80 & 634,25 & 194,16 & 480,05 & 140,57 & 680,32 & 202,65 \\
$\mathrm{EOER}_{\mathrm{Q} 1}$ & 121,60 & 128,27 & 201,38 & 169,33 & 66,67 & 62,96 & 120,03 & 132,61 \\
$\mathrm{EOER}_{\mathrm{Q} 4}$ & 144,00 & 134,89 & 164,54 & 173,15 & 76,30 & 67,67 & 181,44 & 130,52 \\
\hline
\end{tabular}

*dados per capita

Fonte: dados da pesquisa.

Percebe-se por meio da Tabela 7 que os municípios com menor PIB Per Capita (Q1), tanto em nível de análise geral quanto estadual, apresentam uma média menor de Distribuição Tributária e Execução Orçamentária nas três áreas que os municípios de PIB Per Capita superior (Q4). Esses resultados são preocupantes, pois, possuindo os municípios com menor PIB Per Capita também menor distribuição e execução nas três áreas, dificilmente poderão apresentar melhores indicadores econômicos futuros. Nesse sentido, municípios com melhores índices de PIB Per Capita podem estar sendo beneficiados pelo atual modelo de distribuição tributária, consequentemente, influenciando na execução de maior volume de recursos nas três áreas pesquisadas, divergindo do real objetivo da maioria dos mecanismos distributivos da estrutura tributária, que visam reduzir as diferenças regionais.

Na Tabela 8 são apresentados os resultados da Correlação de Pearson que possibilitam o teste das hipóteses H2a, $\mathrm{H} 2 \mathrm{~b}$ e $\mathrm{H} 2 \mathrm{c}$ a nível geral e estadual.

Tabela 8 - Análise de correlação da Distribuição Tributária com a Execução Orçamentária das áreas pesquisadas Quartil PIB Per Capita

\begin{tabular}{|c|c|c|c|c|c|}
\hline $\begin{array}{l}\text { Grupo } \\
\text { amostral }\end{array}$ & Variáveis & $\begin{array}{c}\text { Correlação (r) } \\
\text { de Pearson }\end{array}$ & $\begin{array}{c}\text { Coeficiente de } \\
\text { Determinação } \\
\text { (r2) }\end{array}$ & Sig. $(\alpha)$ & $\begin{array}{l}\text { Status da } \\
\text { hipótese }\end{array}$ \\
\hline \multirow{6}{*}{ Geral } & $\mathrm{DT}_{\mathrm{Q} 1}$ e $\mathrm{EOS}_{\mathrm{Q} 1}$ & $0,892^{\star \star}$ & 0,796 & 0,000 & H2a - Suportada \\
\hline & $\mathrm{DT}_{\mathrm{Q} 1}$ e $\mathrm{EOE}_{\mathrm{Q} 1}$ & $0,754^{\star \star}$ & 0,569 & 0,000 & H2b - Suportada \\
\hline & $\mathrm{DT}_{\mathrm{Q} 1}$ e $\mathrm{EOER}_{\mathrm{Q} 1}$ & $0,812^{\star \star}$ & 0,659 & 0,000 & H2c - Suportada \\
\hline & $\mathrm{DT}_{\mathrm{Q} 4}$ e $\mathrm{EOS}_{\mathrm{Q} 4}$ & $0,882^{\star *}$ & 0,778 & 0,000 & H2a - Suportada \\
\hline & $\mathrm{DT}_{\mathrm{Q} 4}$ e $\mathrm{EOE}_{\mathrm{Q} 4}$ & 0,780 ** & 0,608 & 0,000 & H2b - Suportada \\
\hline & $\mathrm{DT}_{\mathrm{Q} 4}$ e EOER $\mathrm{Q}_{\mathrm{Q}}$ & 0,740 ** & 0,548 & 0,000 & H2c - Suportada \\
\hline \multirow{6}{*}{ SC } & $\mathrm{DT}_{\mathrm{Q} 1}$ e $\mathrm{EOS}_{\mathrm{Q} 1}$ & 0,940 ** & 0,884 & 0,000 & $\mathrm{H} 2 \mathrm{a}_{\mathrm{sc}}$ - Suportada \\
\hline & $\mathrm{DT}_{\mathrm{Q} 1}$ e $\mathrm{EOE}_{\mathrm{Q} 1}$ & $0,755^{\star \star}$ & 0,570 & 0,000 & $\mathrm{H} 2 \mathrm{~b}_{\mathrm{sc}}$ - Suportada \\
\hline & $\mathrm{DT}_{\mathrm{Q} 1}$ e EOER $\mathrm{Q}_{\mathrm{Q} 1}$ & $0,908^{\star \star}$ & 0,824 & 0,000 & $\mathrm{H} 2 \mathrm{c}_{\mathrm{sC}}$ - Suportada \\
\hline & $\mathrm{DT}_{\mathrm{Q} 4}$ e $\mathrm{EOS}_{\mathrm{Q} 4}$ & $0,826^{\star *}$ & 0,682 & 0,000 & $\mathrm{H} 2 \mathrm{a}_{\mathrm{sC}}$ - Suportada \\
\hline & $\mathrm{DT}_{\mathrm{Q} 4}$ e $\mathrm{EOE}_{\mathrm{Q} 4}$ & $0,720^{\star *}$ & 0,518 & 0,000 & $\mathrm{H} 2 \mathrm{~b}_{\mathrm{sc}}$ - Suportada \\
\hline & $\mathrm{DT}_{\mathrm{Q} 4}$ e EOER $\mathrm{Q}_{\mathrm{Q}}$ & $0,842^{\star *}$ & 0,709 & 0,000 & $\mathrm{H} 2 \mathrm{c}_{\mathrm{sc}}$ - Suportada \\
\hline
\end{tabular}




\begin{tabular}{|c|c|c|c|c|c|}
\hline $\begin{array}{l}\text { Grupo } \\
\text { amostral }\end{array}$ & Variáveis & $\begin{array}{c}\text { Correlação (r) } \\
\text { de Pearson }\end{array}$ & $\begin{array}{l}\text { Coeficiente de } \\
\text { Determinação } \\
\text { (r2) }\end{array}$ & Sig. $(\alpha)$ & $\begin{array}{l}\text { Status da } \\
\text { hipótese }\end{array}$ \\
\hline \multirow{6}{*}{ PR } & $\mathrm{DT}_{\mathrm{Q} 1}$ e $\mathrm{EOS}_{\mathrm{Q} 1}$ & $0,870^{\star *}$ & 0,757 & 0,000 & $\mathrm{H} 2 \mathrm{a}_{\mathrm{PR}}$ - Suportada \\
\hline & $\mathrm{DT}_{\mathrm{Q} 1}$ e $\mathrm{EOE}_{\mathrm{Q} 1}$ & $0,761^{\star \star}$ & 0,579 & 0,000 & $\mathrm{H} 2 \mathrm{~b}_{\mathrm{PR}}$ - Suportada \\
\hline & $\mathrm{DT}_{\mathrm{Q} 1}$ e EOER $\mathrm{Q}_{\mathrm{Q} 1}$ & $0,794^{\star *}$ & 0,630 & 0,000 & $\mathrm{H} 2 \mathrm{c}_{\mathrm{PR}}$ - Suportada \\
\hline & $\mathrm{DT}_{\mathrm{Q} 4}$ e $\mathrm{EOS}_{\mathrm{Q} 4}$ & $0,704^{\star \star}$ & 0,496 & 0,000 & $\mathrm{H} 2 \mathrm{a}_{\mathrm{PR}}$ - Suportada \\
\hline & $\mathrm{DT}_{\mathrm{Q} 4} \mathrm{eEOE}_{\mathrm{Q} 4}$ & $0,778^{\star *}$ & 0,605 & 0,000 & $\mathrm{H} 2 \mathrm{~b}_{\mathrm{PR}}$ - Suportada \\
\hline & $\mathrm{DT}_{\mathrm{Q} 4}$ e EOER $\mathrm{Q}_{\mathrm{Q}}$ & $0,563^{\star *}$ & 0,317 & 0,000 & $\mathrm{H} 2 \mathrm{c}_{\mathrm{PR}}$ - Suportada \\
\hline \multirow{6}{*}{ RS } & $\mathrm{DT}_{\mathrm{Q} 1}$ e $\mathrm{EOS}_{\mathrm{Q} 1}$ & $0,849 * *$ & 0,721 & 0,000 & $\mathrm{H} 2 \mathrm{a}_{\mathrm{RS}}$ - Suportada \\
\hline & $\mathrm{DT}_{\mathrm{Q} 1}$ e $\mathrm{EOE}_{\mathrm{Q} 1}$ & $0,655^{\star *}$ & 0,429 & 0,000 & $\mathrm{H} 2 \mathrm{~b}_{\mathrm{RS}}$ - Suportada \\
\hline & $\mathrm{DT}_{\mathrm{Q} 1}$ e EOER $\mathrm{Q}_{\mathrm{Q}}$ & $0,825^{\star \star}$ & 0,681 & 0,000 & $\mathrm{H} 2 \mathrm{c}_{\mathrm{RS}}$ - Suportada \\
\hline & $\mathrm{DT}_{\mathrm{Q} 4}$ e $\mathrm{EOS}_{\mathrm{Q} 4}$ & 0,920 ** & 0,846 & 0,000 & $\mathrm{H} 2 \mathrm{a}_{\mathrm{RS}}$ - Suportada \\
\hline & $\mathrm{DT}_{\mathrm{Q} 4}$ e $\mathrm{EOE}_{\mathrm{Q} 4}$ & $0,816^{\star \star}$ & 0,666 & 0,000 & $\mathrm{H} 2 \mathrm{~b}_{\mathrm{RS}}$ - Suportada \\
\hline & $\mathrm{DT}_{\mathrm{Q} 4}$ e EOER $\mathrm{Q}_{\mathrm{Q}}$ & $0,723^{\star *}$ & 0,523 & 0,000 & $\mathrm{H} 2 \mathrm{c}_{\mathrm{RS}}$ - Suportada \\
\hline
\end{tabular}

**A correlação é significativa no nível 0,01 (2 extremidades)

Fonte: dados da pesquisa.

Os achados da Tabela 8 demonstram um efeito significativo das correlações entre os conjuntos de variáveis testadas (sig. $\leq 0,05)$. Além disso, percebe-se uma correlação de efeito médio à grande em todos os conjuntos de variáveis e grupos amostrais. Portanto, a Execução Orçamentária das áreas da saúde, educação e emprego e renda se relaciona com a Distribuição Tributária independentemente do PIB Per Capita dos municípios. Assim, os resultados indicam que as três hipóteses são suportadas, pois existe relação entre Distribuição Tributária e Execução Orçamentária das três áreas pesquisadas quando os municípios são analisados de forma conjunta (região sul) ou por quartis de PIB Per Capita por estado.

Já a Contribuição Tributária Per Capita corresponde ao segundo indicador econômico utilizado para categorizar os municípios da amostra. A sua escolha se justifica pela importância na formação do "bolo" arrecadatório estadual e federal. Na Tabela 9 apresentam-se as médias e desvio-padrão da Distribuição Tributária e Execução Orçamentária das três áreas pesquisadas, correspondentes aos municípios com menor e maior Contribuição Tributária Per Capita.

Tabela 9 - Análise descritiva das variáveis estudadas - Quartil Contribuição Tributária Per Capita

\begin{tabular}{c|c|c|c|c|c|c|c|c}
\hline \multirow{2}{*}{ Variável } & \multicolumn{2}{|c|}{ Amostra Geral } & \multicolumn{2}{c|}{ SC } & \multicolumn{2}{c}{ PR } & \multicolumn{2}{c}{ RS } \\
\cline { 2 - 9 } & Média* & DP & Média* & DP & Média* & DP & Média* & DP \\
\hline DT $_{\text {Q1 }}$ & $2.766,65$ & $3.793,34$ & $2.660,43$ & 974,76 & $1.750,61$ & 502,15 & $2.505,38$ & 741,70 \\
DT $_{\text {Q4 }}$ & $1.701,07$ & 820,35 & $1.466,50$ & 533,10 & $1.260,13$ & 537,54 & $1.636,13$ & $1.056,39$ \\
EOS $_{\text {Q1 }}$ & 567,79 & 194,87 & 594,56 & 211,99 & 426,19 & 109,65 & 527,81 & 173,18 \\
EOS $_{\text {Q4 }}$ & 460,75 & 177,64 & 406,76 & 123,65 & 344,29 & 125,93 & 376,40 & 214,13 \\
EOE $_{\text {Q1 }}$ & 597,21 & 197,63 & 645,95 & 196,97 & 426,70 & 101,82 & 563,02 & 165,85 \\
EOE $_{\text {Q4 }}$ & 506,73 & 156,42 & 450,25 & 109,30 & 340,37 & 119,79 & 451,15 & 166,52 \\
EOER $_{\text {Q1 }}$ & 174,40 & 159,88 & 295,66 & 209,53 & 87,05 & 72,38 & 198,58 & 144,55 \\
EOER $_{\text {Q4 }}$ & 96,22 & 102,73 & 90,46 & 74,48 & 59,33 & 58,61 & 104,33 & 105,59 \\
\hline
\end{tabular}

Fonte: dados da pesquisa.

De forma inversa ao indicador PIB Per Capita, os municípios com menor Contribuição Tributária Per Capita (Q1) apresentam uma média maior de Distribuição Tributária e Execução Orçamentária nas três áreas. Isso evidencia que, à medida que os municípios aumentam sua Contribuição Tributária Per Capita, a Distribuição Tributária e a Execução 
Orçamentária não acompanham esse aumento. Isso se deve especialmente ao modelo distributivo que vincula um conjunto de transferências a fatores diferentes da contribuição tributária, como população, número de alunos, capacidade de captação de recursos por emendas parlamentares, entre outros.

Para verificar as hipóteses H3a, H3b e H3c realizou-se a análise da correlação de Pearson, apresentada na Tabela 10.

Tabela 10 - Análise de correlação da Distribuição Tributária com a Execução Orçamentária das áreas pesquisadas Quartil Contribuição Tributária Per Capita

\begin{tabular}{|c|c|c|c|c|c|}
\hline $\begin{array}{l}\text { Grupo } \\
\text { amostral }\end{array}$ & Variáveis & $\begin{array}{c}\text { Correlação (r) } \\
\text { de Pearson }\end{array}$ & $\begin{array}{c}\text { Coeficiente de } \\
\text { Determinação } \\
\text { (r2) }\end{array}$ & Sig. $(\alpha)$ & $\begin{array}{l}\text { Status da } \\
\text { hipótese }\end{array}$ \\
\hline \multirow{6}{*}{ Geral } & $\mathrm{DT}_{\mathrm{Q} 1}$ e $\mathrm{EOS}_{\mathrm{Q} 1}$ & $0,187^{\star}$ & 0,035 & 0,023 & H3a - Suportada \\
\hline & $\mathrm{DT}_{\mathrm{Q} 1}$ e $\mathrm{EOE}_{\mathrm{Q} 1}$ & 0,159 & 0,025 & 0,053 & $\begin{array}{l}\text { H3b-Não } \\
\text { Suportada }\end{array}$ \\
\hline & $\mathrm{DT}_{\mathrm{Q} 1}$ e EOER $\mathrm{Q}_{\mathrm{Q}}$ & 0,104 & 0,011 & 0,208 & $\begin{array}{l}\text { H3c-Não } \\
\text { Suportada }\end{array}$ \\
\hline & $\mathrm{DT}_{\mathrm{Q} 4}$ e $\mathrm{EOS}_{\mathrm{Q} 4}$ & $0,757^{\star \star}$ & 0,573 & 0,000 & H3a - Suportada \\
\hline & $\mathrm{DT}_{\mathrm{Q} 4}$ e $\mathrm{EOE}_{\mathrm{Q} 4}$ & $0,788^{\star \star}$ & 0,621 & 0,000 & H3b - Suportada \\
\hline & $\mathrm{DT}_{\mathrm{Q} 4} \mathrm{e} \mathrm{EOER}_{\mathrm{Q} 4}$ & $0,764^{\star \star}$ & 0,584 & 0,000 & H3c - Suportada \\
\hline \multirow{6}{*}{ SC } & $\mathrm{DT}_{\mathrm{Q} 1}$ e EOS $\mathrm{Q}_{\mathrm{Q}}$ & $0,907^{\star \star}$ & 0,823 & 0,000 & $\mathrm{H} 3 \mathrm{a}_{\mathrm{sC}}$ - Suportada \\
\hline & $\mathrm{DT}_{\mathrm{Q} 1}$ e $\mathrm{EOE}_{\mathrm{Q} 1}$ & $0,536^{\star *}$ & 0,287 & 0,002 & $\mathrm{H} 3 \mathrm{~b}_{\mathrm{sc}}$ - Suportada \\
\hline & $\mathrm{DT}_{\mathrm{Q} 1}$ e EOER $\mathrm{Q}_{\mathrm{Q}}$ & $0,766^{\star \star}$ & 0,587 & 0,000 & $\mathrm{H} 3 \mathrm{c}_{\mathrm{SC}}$ - Suportada \\
\hline & $\mathrm{DT}_{\mathrm{Q} 4}$ e $\mathrm{EOS}_{\mathrm{Q} 4}$ & $0,623^{\star *}$ & 0,388 & 0,000 & $\mathrm{H} 3 \mathrm{a}_{\mathrm{sc}}$ - Suportada \\
\hline & $\mathrm{DT}_{\mathrm{Q} 4}$ e $\mathrm{EOE}_{\mathrm{Q} 4}$ & $0,761^{\star \star}$ & 0,579 & 0,000 & $\mathrm{H}_{3} \mathrm{~b}_{\mathrm{SC}}$ - Suportada \\
\hline & $\mathrm{DT}_{\mathrm{Q} 4}$ e EOER $_{\mathrm{Q} 4}$ & $0,794^{\star *}$ & 0,630 & 0,000 & H3c $\mathrm{sc}_{\mathrm{SC}}$ - Suportada \\
\hline \multirow{6}{*}{ PR } & $\mathrm{DT}_{\mathrm{Q} 1}$ e $\mathrm{EOS}_{\mathrm{Q} 1}$ & 0,879 ** & 0,773 & 0,000 & $\mathrm{H} 3 \mathrm{a}_{\mathrm{PR}}$ - Suportada \\
\hline & $\mathrm{DT}_{\mathrm{Q} 1}$ e $\mathrm{EOE}_{\mathrm{Q} 1}$ & $0,792^{\star \star}$ & 0,627 & 0,000 & $\mathrm{H} 3 \mathrm{~b}_{\mathrm{PR}}$ - Suportada \\
\hline & $\mathrm{DT}_{\mathrm{Q} 1}$ e EOER $_{\mathrm{Q} 1}$ & $0,441^{\star *}$ & 0,194 & 0,001 & $\mathrm{H}_{3} \mathrm{C}_{\mathrm{PR}}$ - Suportada \\
\hline & $\mathrm{DT}_{\mathrm{Q} 4}$ e $\mathrm{EOS}_{\mathrm{Q} 4}$ & $0,775^{\star \star}$ & 0,601 & 0,000 & $\mathrm{H} 3 \mathrm{a}_{\mathrm{PR}}$ - Suportada \\
\hline & $\mathrm{DT}_{\mathrm{Q} 4}$ e $\mathrm{EOE}_{\mathrm{Q} 4}$ & $0,809 * *$ & 0,654 & 0,000 & $\mathrm{H} 3 \mathrm{~b}_{\mathrm{PR}}$ - Suportada \\
\hline & $\mathrm{DT}_{\mathrm{Q} 4} \mathrm{e} \mathrm{EOER}_{\mathrm{Q} 4}$ & 0,369 ** & 0,136 & 0,008 & $\mathrm{H} 3 \mathrm{c}_{\mathrm{PR}}$ - Suportada \\
\hline \multirow{6}{*}{ RS } & $\mathrm{DT}_{\mathrm{Q} 1}$ e $\mathrm{EOS}_{\mathrm{Q} 1}$ & $0,877^{\star *}$ & 0,769 & 0,000 & $\mathrm{H} 3 \mathrm{a}_{\mathrm{RS}}$ - Suportada \\
\hline & $\mathrm{DT}_{\mathrm{Q} 1}$ e $\mathrm{EOE}_{\mathrm{Q} 1}$ & $0,682^{\star \star}$ & 0,465 & 0,000 & $\mathrm{H} 3 \mathrm{~b}_{\mathrm{RS}}$ - Suportada \\
\hline & $\mathrm{DT}_{\mathrm{Q} 1}$ e EOER $_{\mathrm{Q} 1}$ & $0,569 * \star$ & 0,324 & 0,000 & $\mathrm{H} 3 \mathrm{c}_{\mathrm{RS}}$ - Suportada \\
\hline & $\mathrm{DT}_{\mathrm{Q} 4}$ e $\mathrm{EOS}_{\mathrm{Q} 4}$ & $0,947^{\star \star}$ & 0,897 & 0,000 & $\mathrm{H} 3 \mathrm{a}_{\mathrm{RS}}$ - Suportada \\
\hline & $\mathrm{DT}_{\mathrm{Q} 4}$ e $\mathrm{EOE}_{\mathrm{Q} 4}$ & $0,815^{\star \star}$ & 0,664 & 0,000 & $\mathrm{H} 3 \mathrm{~b}_{\mathrm{RS}}$ - Suportada \\
\hline & $\mathrm{DT}_{\mathrm{Q} 4}$ e $\mathrm{EOER}_{\mathrm{Q} 4}$ & $0,793^{\star *}$ & 0,629 & 0,000 & $\mathrm{H} 3 \mathrm{c}_{\mathrm{RS}}$ - Suportada \\
\hline
\end{tabular}

*. A correlação é significativa no nível 0,05 (2 extremidades).

** A correlação é significativa no nível 0,01 (2 extremidades).

Fonte: dados da pesquisa.

Quando analisados os dados da Tabela 10 por região, percebe-se que todas as hipóteses são suportadas para o Q4. Entretanto, para os quartis que representam os municípios da região sul de menor Contribuição Tributária Per Capita, não é possível verificar relação significativa entre a Distribuição Tributária e a Execução Orçamentária das áreas de educação e emprego e renda. Tal resultado é bastante curioso, tendo em vista que, a nível estadual, esta relação se apresenta significativa. Assim, uma compreensão mais profunda deste cenário se faz necessária, sendo esta uma sugestão de ampliação desta investigação em estudos futuros. Uma análise qualitativa dos gastos realizados pelos municípios deste quartil poderá indicar possíveis explicações para esses resultados. 
Em complemento, ao analisar os dados separadamente nos três estados, percebe-se um efeito significativo das correlações entre todos os conjuntos de variáveis testadas (sig. $\leq 0,05$ ) para o Q1 e Q4. Além disso, percebe-se uma correlação grande na maioria dos conjuntos de variáveis do maior quartil. Desse modo, para a análise a nível estadual, os resultados indicam que as três hipóteses são suportadas, pois existe uma relação significativa entre Distribuição Tributária e Execução Orçamentária das três áreas mesmo quando os municípios são separados em quartis de Contribuição Tributária Per Capita.

A População corresponde ao último indicador demográfico utilizado para categorizar os municípios da amostra. A escolha do indicador se deve por servir de base para distribuição aos municípios de grande parcela dos recursos arrecadados pelos governos estadual e federal. Por meio da Tabela 11 se apresentam as médias e desvio-padrão da Distribuição Tributária e Execução Orçamentária das três áreas pesquisadas, correspondentes aos municípios com menor e maior População.

Tabela 11 - Análise descritiva das variáveis estudadas - Quartil População

\begin{tabular}{|c|c|c|c|c|c|c|c|c|}
\hline \multirow{2}{*}{ Variável } & \multicolumn{2}{|c|}{ Amostra Geral } & \multicolumn{2}{|c|}{ SC } & \multicolumn{2}{|c|}{ PR } & \multicolumn{2}{|c|}{ RS } \\
\hline & Média* & DP & Média* & DP & Média* & DP & Média* & DP \\
\hline $\mathrm{DT}_{\mathrm{Q} 1}$ & $3.274,13$ & 709,57 & $3.397,77$ & 667,12 & $3.404,77$ & $6.348,14$ & $3.586,65$ & 736,69 \\
\hline $\mathrm{DT}_{\mathrm{Q} 4}$ & $1.238,61$ & 330,67 & $1.316,85$ & 308,83 & $1.147,47$ & 343,06 & $1.258,38$ & 312,35 \\
\hline $\mathrm{EOS}_{\mathrm{Q} 1}$ & 736,35 & 156,06 & 758,05 & 161,67 & 597,84 & 132,11 & 795,60 & 149,50 \\
\hline $\mathrm{EOS}_{\mathrm{Q} 4}$ & 362,33 & 127,42 & 408,70 & 120,40 & 351,47 & 137,24 & 340,78 & 117,50 \\
\hline $\mathrm{EOE}_{\mathrm{Q} 1}$ & 719,16 & 173,10 & 778,53 & 168,01 & 572,09 & 120,64 & 743,45 & 181,36 \\
\hline $\mathrm{EOE}_{\mathrm{Q} 4}$ & 431,41 & 112,35 & 494,83 & 101,35 & 385,18 & 116,23 & 433,57 & 98,52 \\
\hline $\mathrm{EOER}_{\mathrm{Q} 1}$ & 290,39 & 179,17 & 365,79 & 188,36 & 103,99 & 77,83 & 339,20 & 161,83 \\
\hline $\mathrm{EOER}_{\mathrm{Q} 4}$ & 48,10 & 34,76 & 54,97 & 29,20 & 35,70 & 26,56 & 54,77 & 42,76 \\
\hline
\end{tabular}

*dados per capita

Fonte: dados da pesquisa.

Percebe-se, por meio da Tabela 11, que os municípios com menor População (Q1) apresentam a média e desvio-padrão maior nas variáveis da Distribuição Tributária e Execução Orçamentária das três áreas, quando comparados com os municípios de População superior (Q4). Isso evidencia que, na medida em que os municípios aumentam sua População, a Distribuição Tributária e a Execução Orçamentária diminuem por habitante. Isso se deve especialmente ao modelo distributivo que estabelece valores fixos de distribuição de recursos por faixas de população, com destaque ao FPM e uma parcela do ICMS.

Nessa linha, Magalhães (2008, p. 17) explica com o FPM que "a relação entre os recursos fiscais disponíveis dos municípios e o tamanho de suas populações são bem representados pelo formato de $U$ ”. O autor complementa que, nos municípios com poucos habitantes, o modelo de distribuição do FPM responde pela grande receita por habitante. À medida que vão sendo avaliados municípios mais populosos, a representatividade do FPM per capita diminui em maior proporção que o aumento da arrecadação própria per capita. A partir de determinado tamanho de município, entretanto, as receitas per capita voltam a crescer, fruto da superior arrecadação própria (Magalhães, 2008).

Para verificar as hipóteses H4a, H4b e H4c apresenta-se a Tabela 12. 
Tabela 12 - Análise do teste de correlação da Distribuição Tributária com a Execução Orçamentária das áreas pesquisadas - Quartil População

\begin{tabular}{|c|c|c|c|c|c|}
\hline $\begin{array}{l}\text { Determinação } \\
\text { (r2) }\end{array}$ & Sig. $(\alpha)$ & $\begin{array}{l}\text { Status da } \\
\text { hipótese }\end{array}$ & $\begin{array}{c}\text { Coeficiente de } \\
\text { Determinação } \\
\text { (r2) }\end{array}$ & Sig. $(\alpha)$ & Status da hipótese \\
\hline \multirow{6}{*}{ Geral } & $\mathrm{DT}_{\mathrm{Q} 1}$ e $\mathrm{EOS}_{\mathrm{Q} 1}$ & $0,847^{\star \star}$ & 0,717 & 0,000 & H4a - Suportada \\
\hline & $\mathrm{DT}_{\mathrm{Q} 1}$ e $\mathrm{EOE}_{\mathrm{Q} 1}$ & $0,576^{\star \star}$ & 0,332 & 0,000 & H4a - Suportada \\
\hline & $\mathrm{DT}_{\mathrm{Q} 1}$ e EOER ${ }_{\mathrm{Q} 1}$ & $0,542^{\star \star}$ & 0,294 & 0,000 & H4b - Suportada \\
\hline & $\mathrm{DT}_{\mathrm{Q} 4}$ e $\mathrm{EOS}_{\mathrm{Q} 4}$ & $0,609 \star \star$ & 0,371 & 0,000 & H4a - Suportada \\
\hline & $\mathrm{DT}_{\mathrm{Q} 4}$ e $\mathrm{EOE}_{\mathrm{Q} 4}$ & $0,712^{\star *}$ & 0,507 & 0,000 & H4b - Suportada \\
\hline & $\mathrm{DT}_{\mathrm{Q} 4}$ e EOER $\mathrm{E}_{\mathrm{Q}}$ & $0,489 \star \star$ & 0,239 & 0,000 & H4c - Suportada \\
\hline \multirow{6}{*}{ SC } & $\mathrm{DT}_{\mathrm{Q} 1}$ e EOS $\mathrm{Q}_{\mathrm{Q} 1}$ & $0,854^{\star \star}$ & 0,729 & 0,000 & $\mathrm{H} 4 \mathrm{a}_{\mathrm{SC}}-$ Suportada \\
\hline & $\mathrm{DT}_{\mathrm{Q} 1}$ e $\mathrm{EOE}_{\mathrm{Q} 1}$ & $0,316^{\star}$ & 0,100 & 0,042 & $\mathrm{H}_{4} \mathrm{~b}_{\mathrm{sC}}-$ Suportada \\
\hline & $\mathrm{DT}_{\mathrm{Q} 1}$ e EOER $\mathrm{Q}_{\mathrm{Q}}$ & $0,731^{\star *}$ & 0,534 & 0,000 & $\mathrm{H} 4 \mathrm{c}_{\mathrm{SC}}$ - Suportada \\
\hline & $\mathrm{DT}_{\mathrm{Q} 4} \mathrm{e} \mathrm{EOS}_{\mathrm{Q} 4}$ & $0,477^{\star *}$ & 0,228 & 0,001 & $\mathrm{H} 4 \mathrm{a}_{\mathrm{SC}}-$ Suportada \\
\hline & $\mathrm{DT}_{\mathrm{Q} 4}$ e $\mathrm{EOE}_{\mathrm{Q} 4}$ & $0,708^{\star *}$ & 0,501 & 0,000 & $\mathrm{H} 4 \mathrm{~b}_{\mathrm{sc}}$ - Suportada \\
\hline & $\mathrm{DT}_{\mathrm{Q} 4}$ e EOER $\mathrm{Q}_{\mathrm{Q}}$ & $0,411^{\star *}$ & 0,169 & 0,007 & $\mathrm{H}_{4} \mathrm{c}_{\mathrm{SC}}$ - Suportada \\
\hline \multirow{6}{*}{ PR } & $\mathrm{DT}_{\mathrm{Q} 1}$ e EOS $\mathrm{Q}_{\mathrm{Q} 1}$ & $-0,069$ & 0,005 & 0,636 & $H 4 a_{P R}-$ Não Suportada \\
\hline & $\mathrm{DT}_{\mathrm{Q} 1}$ e $\mathrm{EOE}_{\mathrm{Q} 1}$ & $-0,021$ & 0,000 & 0,886 & $H 4 b_{P R}-N a \tilde{o}$ Suportada \\
\hline & $\mathrm{DT}_{\mathrm{Q} 1}$ e $\mathrm{EOER}_{\mathrm{Q} 1}$ & $-0,107$ & 0,011 & 0,460 & $H 4 C_{P R}-$ Não Suportada \\
\hline & $\mathrm{DT}_{\mathrm{Q} 4}$ e $\mathrm{EOS}_{\mathrm{Q} 4}$ & $0,626^{\star \star}$ & 0,392 & 0,000 & $\mathrm{H} 4 \mathrm{a}_{\mathrm{PR}}$ - Suportada \\
\hline & $\mathrm{DT}_{\mathrm{Q} 4}$ e $\mathrm{EOE}_{\mathrm{Q} 4}$ & $0,735^{\star \star}$ & 0,540 & 0,000 & $\mathrm{H} 4 \mathrm{~b}_{\mathrm{PR}}$ - Suportada \\
\hline & $\mathrm{DT}_{\mathrm{Q} 4} \mathrm{e} \mathrm{EOER}_{\mathrm{Q} 4}$ & $0,478^{\star \star}$ & 0,228 & 0,000 & $\mathrm{H} 4 \mathrm{c}_{\mathrm{PR}}$ - Suportada \\
\hline \multirow{6}{*}{$\mathrm{RS}$} & $\mathrm{DT}_{\mathrm{Q} 1}$ e EOS $\mathrm{Q}_{\mathrm{Q} 1}$ & $0,816^{\star \star}$ & 0,666 & 0,000 & $\mathrm{H} 4 \mathrm{a}_{\mathrm{RS}}$ - Suportada \\
\hline & $\mathrm{DT}_{\mathrm{Q} 1}$ e $\mathrm{EOE}_{\mathrm{Q} 1}$ & $0,638^{\star \star}$ & 0,407 & 0,000 & $\mathrm{H} 4 \mathrm{~b}_{\mathrm{RS}}$ - Suportada \\
\hline & $\mathrm{DT}_{\mathrm{Q} 1}$ e EOER $\mathrm{E}_{\mathrm{Q}}$ & 0,249 & 0,062 & 0,066 & $H 4 c_{R S}-N a ̃ o$ Suportada \\
\hline & $\mathrm{DT}_{\mathrm{Q} 4} \mathrm{eEOS}_{\mathrm{Q} 4}$ & $0,694^{\star *}$ & 0,482 & 0,000 & $\mathrm{H} 4 \mathrm{a}_{\mathrm{RS}}$ - Suportada \\
\hline & $\mathrm{DT}_{\mathrm{Q} 4}$ e $\mathrm{EOE}_{\mathrm{Q} 4}$ & $0,666^{\star \star}$ & 0,444 & 0,000 & $\mathrm{H} 4 \mathrm{~b}_{\mathrm{RS}}$ - Suportada \\
\hline & $\mathrm{DT}_{\mathrm{Q} 4}$ e EOER $\mathrm{O}_{4}$ & $0,514^{\star *}$ & 0,264 & 0,000 & $\mathrm{H} 4 \mathrm{c}_{\mathrm{RS}}$ - Suportada \\
\hline
\end{tabular}

* A correlação é significativa no nível 0,05 (2 extremidades)

**A correlação é significativa no nível 0,01 (2 extremidades)

Fonte: dados da pesquisa.

Denota-se que há um efeito significativo das correlações entre a maioria dos conjuntos de variáveis testadas (sig. $\leq$ 0,05). Em complemento, identifica-se que a correlação não é tão forte quando analisados os dados a partir de sua população se comparado com PIB Per Capita e Contribuição Tributária Per Capita. Comparativamente, os resultados para o grupo geral (nível regional) e para os estados de SC e RS são bastante semelhantes, indicando, majoritariamente, correlações mais fracas entre a Distribuição Tributária e a Execução Orçamentária da área de Emprego e Renda, e mais fortes para a área da Saúde nos quartis de menor população e de Educação nos de maior população.

Merece destaque o fato de todas as variáveis não apresentarem correlação no Q1 para o estado do PR, incitando análises mais profundas a respeito tanto de eventuais divergências entre nas demonstrações contábeis publicadas no SICONFI e as prestações de contas encaminhadas ao TCE/PR, quanto da configuração das aplicações de percentuais significativos dos recursos distribuídos em outras áreas diferentes das analisadas nesta pesquisa. 


\section{CONSIDERAÇÕES FINAIS}

A presente pesquisa teve como objetivo central verificar se existe relação entre a Distribuição Tributária e a Execução Orçamentária nas áreas da Saúde, Educação e Emprego e Renda. Como objetivo secundário buscou verificar se a relação entre a Distribuição Tributária e Execução Orçamentária nas áreas da Saúde, Educação e Emprego e Renda é alterada quando se avaliam os municípios por categorias de indicadores econômicos e demográficos. Para atingir os objetivos central e secundário propostos foi aplicada a metodologia descritiva, com coleta de dados documentais, de abordagem quantitativa e de corte transversal.

Inicialmente para atingir o objetivo central foi apresentado o cenário da relação entre Distribuição Tributária e Execução Orçamentária nas áreas da saúde, educação e emprego e renda dos 592 municípios integrantes da amostra. Os achados demonstram uma execução orçamentária dos recursos distribuídos muito maior nas áreas de saúde e educação. Os testes de correlação indicam que todas as hipóteses testadas foram suportadas, com exceção da hipótese $H 1_{c P R}$. Tal resultado se justifica, parcialmente, frente as distorções significativas existentes entre os valores totais dos gastos de diversos municípios e suas respectivas aplicações nas três áreas investigadas.

Posteriormente, para atingir o objetivo secundário, analisaram-se os dados a partir de quartis (Q1 e Q4) dos indicadores PIB Per Capita, Contribuição Tributária Per Capita e População. O estudo do PIB Per Capita indicou uma média menor de Distribuição Tributária e Execução Orçamentária para os municípios com PIB inferior (Q1). As hipóteses testadas para este indicador foram significativas, com correlações de efeito médio à grande. Esses resultados indicam que, existe relação entre Distribuição Tributária e Execução Orçamentária das três áreas pesquisadas quando os municípios são analisados de forma conjunta (região sul) ou por quartis de PIB Per Capita por estado.

Em seguida, quando agrupados os municípios pelo indicador Contribuição Tributária Per Capita, identificou-se que os municípios com menor Contribuição Tributária Per Capita (Q1) apresentam uma média maior de Distribuição Tributária e Execução Orçamentária nas três áreas. Em adição, a análise da correlação a partir desse indicador demonstrou uma relação significativa entre praticamente todos os conjuntos de variáveis analisados. No entanto, a correlação é mais forte na maioria dos conjuntos de variáveis para os municípios de maior Contribuição Tributária Per Capita (Q4).

A População correspondeu ao último indicador analisado. Independentemente da análise geral ou por estado da Distribuição Tributária e Execução Orçamentária, os municípios de População inferior (Q1) apresentam médias e desvio padrão maiores. O teste de correlação apresentou um efeito significativo na maioria dos conjuntos de variáveis, no entanto, com uma força menor se comparado com a análise por PIB Per Capita e Contribuição Tributária Per Capita.

Por fim, ao se analisar a relação a partir dos indicadores econômicos e demográficos, infere-se que existe uma correlação significativa na maioria dos conjuntos de variáveis quando analisados de forma geral ou por estado. Os resultados destacam também que, municípios com melhores índices de PIB Per Capita podem estar sendo beneficiados pelo atual modelo distributivo, o que dificulta a melhora desse indicador nos municípios de PIB Per Capita inferior, a partir de suas execuções orçamentárias. Em adição, os resultados mostram uma falha no modelo distributivo, pois, à medida que os municípios aumentam sua Contribuição Tributária Per Capita, a Distribuição Tributária e a Execução Orçamentária não acompanham esse aumento. Finalmente, ao avaliar os dados a partir do indicador demográfico da População, percebe-se a tendência do atual modelo distributivo de, na medida em que os municípios aumentam sua População, a Distribuição Tributária e a Execução Orçamentária diminuem por habitante.

A partir dos resultados encontrados, lança-se uma reflexão sobre a necessidade de revisão do atual modelo distributivo, tendo em vista que Abreu (2001) pontua que municípios com menor População por exemplo, dependem muito mais das transferências intergovernamentais. De outra forma, serve de alerta, que os municípios que mais contribuem para a formação do "bolo" arrecadado pelos estados e união acabam recebendo menores valores Per Capita.

Diante das limitações desse estudo, como o breve período de tempo analisado, bem como a impossibilidade de maior atualização dos dados, recomenda-se para pesquisas futuras ampliar o horizonte temporal, bem como realizar análise quantitativa a partir de outras variáveis, buscando identificar os demais fatores que interferem na Distribuição Tributária e Execução Orçamentária dos municípios.

\section{REFERÊNCIAS}

Abreu, C. C. de. (2001). Instalação de novos municipios em Santa Catarina em 1997: um estudo dos reflexos financeiros (Dissertação de Mestrado). Programa de Pós-graduação em Administração da Universidade Federal de Santa Catarina, Florianópolis, SC, Brasil.

Araújo, R. L. S. (2013). Limites e possibilidades da redução de desigualdades territoriais por meio do financiamento da educação básica. 401 f. Tese (Doutorado em Educação) - Programa de Pós-Graduação da Faculdade de Educação da Universidade de São Paulo, São Paulo.

Arretche, M. (2004). Federalismo e políticas sociais no Brasil: problemas de coordenação e autonomia. Revista São Paulo em Perspectiva, 18 (2), 17-26.

Barbetta, P. A. (2008). Estatística aplicada às Ciências Sociais (7a ed.). Florianópolis: Editora da UFSC.

Brasil. (2004). Constituição da República Federativa do Brasil: 1988. (23a ed.) Brasília: Câmara dos Deputados, Coordenação de Publicações. 
Brito, J. R. S. de. (2011). Efeitos das transferências intergovernamentais sobre as finanças públicas dos municipios do Estado do Rio Grande do Norte (2001 - 2010 (Dissertação de Mestrado). Programa de Pós-Graduação em Economia da Universidade Federal do Rio Grande do Norte, Natal, RN, Brasil.

Bronuzi Jr., A. C., Ferreira, M. A. M., Abrantes, L. A., \& Arantes, V. A. (2011). Efeitos das transferências intergovernamentais e arrecadação tributária sobre os indicadores sociais da saúde e educação em Minas Gerais. RIC-Revista de Informação Contábil, 5(2), 99121. Recuperado de https://periodicos.ufpe.br/revistas/ricontabeis/article/view/7930/8007

Burgo, V. (2013). O impacto do federalismo fiscal no processo de controle jurisdicional de políticas públicas. 199 f. Tese (Doutorado em Direito) - Faculdade de Direito da Universidade de São Paulo, São Paulo,

Carvalho, J. A. M. de. (2010). O federalismo fiscal brasileiro e o desvio de recursos (Tese de Doutorado). Faculdade de Direito da Universidade de São Paulo (Departamento de Direito Econômico e Financeiro), São Paulo, SP, Brasil.

Conti, J. M. (2001). Federalismo fiscal e fundos de participação. São Paulo: Editora Juarez de Oliveira.

Cossio, F. A. B.(2002). Ensaios sobre Federalismo Fiscal (Tese de Doutorado). Departamento de Economia, Pontifícia Universidade Católica do Rio de Janeiro, Rio de Janeiro, RJ, Brasil.

Field, A. (2009). Descobrindo a Estatística usando o SPSS. (2a ed.). Porto Alegre: Artmed.

Fonseca, E. G. da. (2017). Roda Viva. São Paulo. TV Cultura - Fundação Padre Anchieta, 24 de abril, 2017. Programa de TV. Recuperado de http://tvcultura.com.br/videos/60695_roda-vivaeduardo-giannetti-da-fonseca-24-04-2017.html

Hair, Jr. J. F., Babin, B., Money, A. H., \& Samouel, P. (2005). Fundamentos de métodos de pesquisa em administração. Porto Alegre: Bookman.

Januzzi, P. M. (2012) Indicadores Sociais no Brasil: conceitos, fontes de dados e aplicações. (5a ed.). São Paulo: Editora Alínea.

Lima, L. D. de. (2006) Federalismo, relações fiscais e financiamento do Sistema Único de Saúde: a distribuição de receitas vinculadas à saúde nos orçamentos municipais e estaduais. (Tese de Doutorado). Curso de Pós-Graduação em Saúde Coletiva - Instituto de Medicina Social da Universidade do Estado do Rio de Janeiro, Rio de Janeiro, RJ, Brasil.

Liparizi, F. B. (2006) Descentralização fiscal no Brasil. Evolução e tendências recentes. (Dissertação de Mestrado). Programa de Pós-Graduação em Administração da Universidade de Brasília, Brasília, DF, Brasil.

Magalhães, J. C. (2008). Emancipação político-administrativa de municípios no Brasil. In: Carvalho, A. X. Y; Albuquerque, C. W.; Mota, J. A.; Piancastelli, M. (Org). Dinâmica dos municípios. Departamento de Estudos Regionais e Urbanos (DIRUR) do Instituto de Pesquisa Econômica Aplicada (Ipea) (pp. 13-52). Brasilia: Ipea.

Massardi, W. de O., \& Abrantes, L. A. (2014). Classificação dos municípios mineiros em relação à composição de suas receitas. Revista de Gestão, Finanças e Contabilidade, 4(1), 144-161. Recuperado de http://www.revistas.uneb.br/index.php/financ/article/ view/443

Massardi, W. de O., \& Abrantes, L. A. (2015). Esforço fiscal, dependência do FPM e desenvolvimento socioeconômico: um estudo aplicado aos municípios de Minas Gerais. REGE-Revista de Gestão, 22(3), 295-313. Recuperado de https://www.sciencedirect.com/ science/article/pii/S1809227616301229

Matias-Pereira, J. (2010). Finanças públicas: a política orçamentária no Brasil. (5a ed.). São Paulo: Atlas.

Moratta, N. G. (2015). A participação das transferências intergovernamentais no crescimento econômico dos municípios: um estudo no Estado de Santa Catarina (Dissertação de Mestrado). Programa de Pós-Graduação em Planejamento e Governança Pública da Universidade Tecnológica Federal do Paraná (UTFPR), Curitiba, PR, Brasil.

Nascimento, J. dos S. (2010). Efeito das transferências financeiras sobre os gastos e a arrecadação dos municipios brasileiros (Tese de Doutorado). Programa de Pós-Graduação em Economia Aplicada da Universidade Federal de Viçosa, Viçosa, MG, Brasil.

Nazareth, P. A. C. de P. (2015). Descentralização fiscal e autonomia municipal: elementos para o debate. Revista Paranaense de Desenvolvimento, 36(128), v. 36,117-132.

Oliveira, J. G. de. (2010). Uma análise do impacto das emancipações sobre a distribuição orçamentária entre os municípios gaúchos: 1989 - 2007. 2010. 67 f. Dissertação (Mestrado em Economia) - Programa de Pós-Graduação em Economia da Pontifícia Universidade Católica do Rio Grande do Sul.

PNUD - PROGRAMA DAS NAÇÕES UNIDAS PARA O DESENVOLVIMENTO. (2016). O que é IDH. Recuperado de http://www. pnud.org.br/IDH/IDH.aspx?indiceAccordion=0\&li=li_IDH\#.

Politi, R., \& Mattos, E. (2016). Aspectos equitativos e eficientes das transferências intergovernamentais: uma investigação para os municípios brasileiros. Anais do Encontro Nacional de Economia. Niterói. Niterói, RJ, Brasil, 43. Recuperado de http://econpapers.repec. org/paper/anpen2015/075.htmCD-ROM

Porsse, A. A. (2005). Competição tributária regional, externalidades fiscais e federalismo no Brasil: uma abordagem de equilibrio geral computável. (Tese de Doutorado). Programa de Pós-Graduação em Economia da Faculdade de Ciências Econômicas da Universidade Federal do Rio Grande do Sul, Rio Grande do Sul, RS, Brasil.

Prado, S. (2003). Distribuição intergovernamental de recursos na Federação brasileira. In: Rezende, F., \& Oliveira, F. A. de (orgs.), 2003, Descentralização e Federalismo Fiscal no Brasil: Desafios da Reforma Tributária. Rio de Janeiro, Konrad Adenauer Stiftung, 336p.

Rebouças, A. H. M. (2014). A impositividade das emendas parlamentares ao orçamento à luz do principio constitucional do planejamento público: Um exame sob as perspectivas da "resposta correta" e do "direito como integridade" em Dworkin e das pré-compreensões em Gadamer. (Tese de Doutorado). Programa de Pós-Graduação da Faculdade de Direito da Universidade de Brasília (UnB), Brasília, DF, Brasil. 
Rodrigues, M. da P. (2004). Esforço fiscal próprio dos municípios catarinenses e transferências intergovernamentais (Dissertação de Mestrado). Programa de Pós-Graduação em Economia, Centro Sócio Econômico da Universidade Federal de Santa Catarina, Florianópolis, SC, Brasil.

Sakurai, S. N. (2013). Efeitos assimétricos das transferências governamentais sobre os gastos públicos locais: evidências em painel para os municípios brasileiros. Revista Pesquisa e Planejamento Econômico, 43(2),309-332.

Santos, A. M. S. P. (2012). Descentralização e autonomia municipal: uma análise das transformações institucionais no federalismo Brasileiro. Revista Geo UERJ, 2(23), 825-852.

Silva, M. S. (2002). Federalismo fiscal no Brasil: arrecadação, transferências e disponibilidades (1988-2000). (Dissertação de Mestrado). Escola Brasileira de Administração Pública e Empresarial - Fundação Getúlio Vargas, Rio de Janeiro, RJ, Brasil.

Tedesco, P. C. (2014). A guerra fiscal travada entre os Estados da Federação na exigência do Imposto sobre Operações relativas à Circulação de Mercadorias e Serviços (ICMS): exigência, pelo Estado de Destino, do ICMS não recolhido no Estado de Origem. $2014.173 \mathrm{f}$. Dissertação (Mestrado em Direito Econômico e Financeiro) - Faculdade de Direito da Universidade de São Paulo.

Veloso, J. F. A. (2008). As transferências intergovernamentais e o esforço tributário municipal: uma análise do Fundo de Participação dos Municipios (FPM) (Dissertação de Mestrado). Programa de Pós-Graduação em Economia de Empresas da Universidade Católica de Brasília, Brasilia, DF, Brasil.

Vieira, M. A., Abrantes, L. A., Almeida, F. M., Silva, T. A., \& Ferreira, M. A. M. (2017). Condicionantes da Arrecadação Tributária: Uma Análise para os Municípios de Minas Gerais. Enfoque Reflexão Contábil, 36(2), 147-162. 